\title{
Eine Neue Art von der Gattung Oribotritia JACOT (Acarina : Oribatei) von
}

\author{
Jun-ichi AOKI \\ Institut der Angewandten Entomologie, Landwirtschaftliche \\ Fakultät, Tokio Universität, Japan
}

\section{Oribotritia kishidai sp. nov.}

Das Propodosoma ist, seitlich gesehen, länglich schmal. Seine Borsten sind sehr lang, von oben gesenen, in 2 geraden Reihen geordnet (Fig. B). Die Lamellarhaare und Interlamellarhaare sind aufrecht und abstehend. Die Rostralhaare etwas dem Propodosoma anligend (Fig. A). Die Randzone des Propodosomas verschwinden ungefähr neben den Ansatzstellen der Rostralhaare. Die pseudostigmatischen Organe sind fein, borstenförming, kürzer als die Rostralhaare (Fig. B). Die Carinae sind scwhwach entwickelt. Jedes Beinpaar mit 3 Krallen verschen, von denen die mittele etwas dicker und kürzer als die beidenseitigen. Das Hysterosoma ist niedrig am vorderen Teile. Die Rückenborsten sind ziemlich lang, aufrecht stehend (Fig. A). Auf den Genitalschilden finden sich 10 Paar Borsten, die voneinander mit etwa gleicher $Z$ wischenraum geordnet, genau aber gesagt, nach vorn ein wenig anliegender werden (Fig. C,D). Die Analschilde hat an den weit hintertı Teilen nur 1 Paar Borsten. Die die Genitalschilde und Analschilde umfassenden, schmalen Platten haben neben dem Verbindungseinstück 1 Paar der gerundeten Einschnitten und 2 Paar Borsten an den vorderen, äusseren Teilen und 4 Paar Borsten dicht neben den Analschilden, von denen das hinterste Paar beträchtlich lang (Fig. D). Ich habe bei 3 Exemplaren folgende Masse festgestellt: (mm)

\begin{tabular}{l|c|c|c}
\hline & $\mathrm{a}$ (Holotypus) & $\mathrm{b}$ & $\mathrm{c}$ \\
\hline Länge des Hyst. & 1.04 & 1.13 & - \\
Höhe & 0.75 & 0.76 & - \\
Länge des Prop. & 0.54 & 0.59 & 0.50 \\
Breite des Prop. & - & - & 0.44 \\
Länge des Rosth. & 0.21 & 0.23 & 0.23 \\
Lange des Lamlh. & 0.27 & 0.27 & - \\
Länge des Interlh. & 0.31 & 0.32 & - \\
\hline
\end{tabular}

Diese Art unterscheidet sich von anderen Oribotritia-Arten durch die Gestalt 


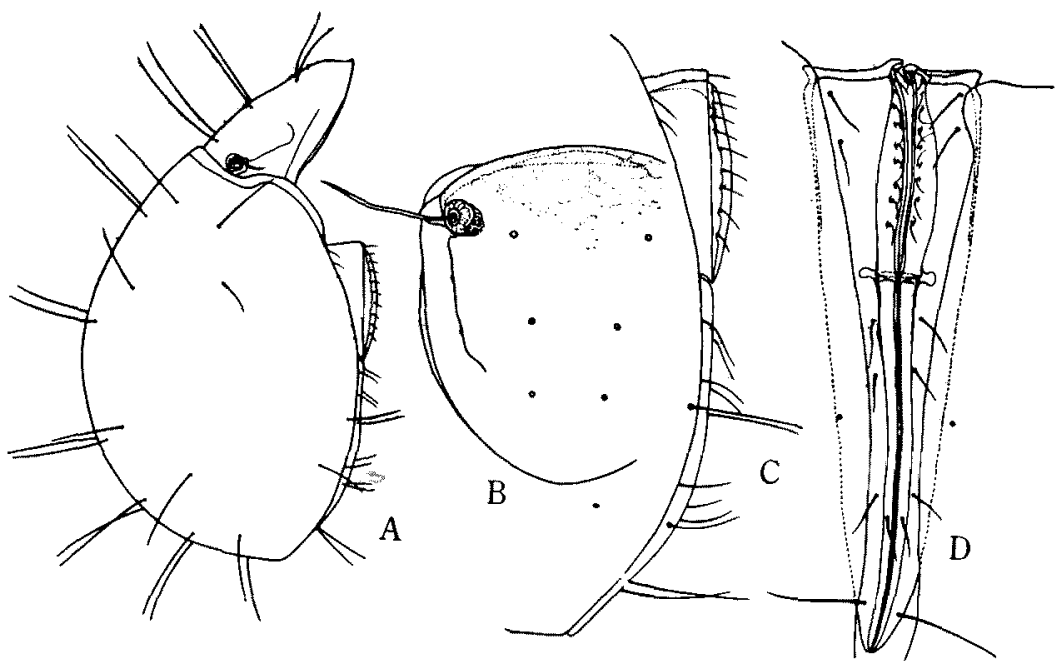

Oribotritia kishidai sp. nov.

A) lateral. B) das Propodosoma (die Borsten nur die Ansatzstelle gezeigt)

C) das Genital-und Analfeld (lateral). D) das Genital-und Analfeld (ventral).

und Anordnung der Borsten am Propodosoma, die sehr lang, aufrecht und in 2 geraden Linien geordnet sind. Dicht hinter dem Verbindungseinstück von Genital. und Analschilden findet sich keine Borste, wie bei O. decumana, O. glabrata und $O$. virginiensis. Ferner die Rückenborsten des Hysterosomas scheinen viel länger als die der anderen Arten. Ich habe einem Weibchen 4 verhältnismässig kleine Eier erkannt, die mit vielen, wellenförmigen Runzeln und an jeder Spitze eine kleine Vorsprung versehen sind.

HOLOTYPUS : aus Probe Nr. 46 : Kare-Numa (im $1600 \mathrm{~m}$ Höhe), Nikko, Tochigi-Präf., Japan. erbeutet von mir in faulem Laub aus dunklem, feuchtem Nadelwalde.

PARATYPEN : 2 Expl. aus derselben Probe. Holotypus zusammen mit Paratypen in meiner Sammlung.

\section{Literatur}

Balogh, J. (1943) Magyarország Páncelosatkái (conspectus oribateorum hungariae). Matem.és Termész. Közlemenyekt XXXIX, Kötet 5. Szám. Jacot, A.P. (1930) Oribatid mites of the subfamily Phthiracarinae of the northeastern. United States. Proc. Boston Soc. Nat. Hist. 39 (6) : 209-261. - (1933) Phthiracarid mites of 
Florida. Journ. Elisha Mitchell Sci. Soc. $48: 232-267$. Sellnick, M. (1928) Formenkreis : Hornmilben, Oribatei. In : Brohmer, Ehrmann, Ulmar : Tierwelt Mitteleuroprs III. Willmann, C. (1931) Tierwelt Deutschl. 22 Teil : 79-200.

摘 要

落葉・腐植・苔などの中に自由生活を営むササラダニ上科 Oribatei は，本邦にも多 種類棲息していると拘らず, 従来殆と注目されていない棣である.ここにはその中, 体 を球形にまるめて口器や脚をすへてて体内にしまい込むことのでる特異な一群であるイ レコタニ科 Phthiracaridae に属する一新種キシタオオイレコタニ Oribotritia kishidai sp. nov. を日光涸沼より記録・記载した．種名は常々括世話になる岸田久吉氏に棒げ た.

\section{ACTA ARACHNOLOGICA \\ VOL. XVI, NO. 1}

昭和33年9月10日印即・昭和33年9月25日究行

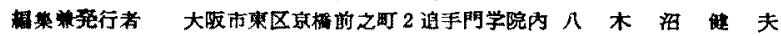

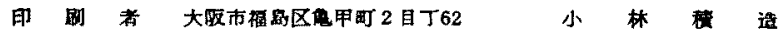

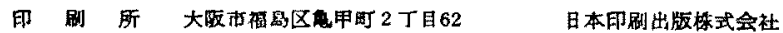

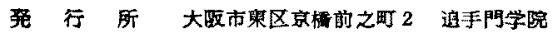

東 亚 蜘 学 会

勧萿果93947番・5929翻

振大㫟 187888 番 